\title{
Enrichment dynamics for advanced reactor HALEU support
}

\author{
Amanda M. Bachmann ${ }^{1, *} \mathbb{0}$, Roberto Fairhurst-Agosta ${ }^{1}$, Zoë Richter ${ }^{1}$, Nathan Ryan ${ }^{1}$, \\ and Madicken Munk ${ }^{1,2}$ \\ ${ }^{1}$ Department of Nuclear, Plasma, and Radiological Engineering, University of Illinois at Urbana-Champaign, \\ Urbana, IL 61801, USA \\ ${ }^{2}$ National Center for Supercomputing Applications, University of Illinois at Urbana-Champaign, Urbana, IL 61801, \\ USA
}

Received: 15 July 2021 / Received in final form: 6 October 2021 / Accepted: 8 November 2021

\begin{abstract}
Transitioning to High Assay Low Enriched Uranium-fueled reactors will alter the material requirements of the current nuclear fuel cycle, in terms of the mass of enriched uranium and Separative Work Unit capacity. This work simulates multiple fuel cycle scenarios using Cyclus to compare how the type of the advanced reactor deployed and the energy growth demand affect the material requirements of the transition to High Assay Low Enriched Uranium-fueled reactors. Fuel cycle scenarios considered include the current fleet of Light Water Reactors in the U.S. as well as a no-growth and a 1\% growth transition to either the Ultra Safe Nuclear Corporation Micro Modular Reactor or the X-energy Xe-100 reactor from the current fleet of U.S. Light Water Reactors. This work explored parameters of interest including the number of advanced reactors deployed, the mass of enriched uranium sent to the reactors, and the Separative Work Unit capacity required to enrich natural uranium for the reactors. Deploying Micro Modular Reactors requires a higher average mass and Separative Work Unit capacity than deploying Xe-100 reactors, and a lower enriched uranium mass and a higher Separative Work Unity capacity than required to fuel Light Water Reactors before the transition. Fueling Xe-100 reactors requires less enriched uranium and Separative Work Unit capacity than fueling Light Water Reactors before the transition.
\end{abstract}

\section{Introduction}

Most Light Water Reactors (LWRs) operating in the U.S. are slated to retire before 2050; meaning that if nuclear power is to continue providing a significant portion of energy in the U.S., new reactors will need to be built. New reactors are likely to be advanced reactor designs, many of which require High-Assay Low-Enriched Uranium (HALEU) for fuel. HALEU is uranium enriched between $5-20 \%{ }^{235} \mathrm{U}$, compared to the Low-Enriched Uranium (LEU) enriched to less than $5 \%{ }^{235} \mathrm{U}$ that fuels current LWRs. HALEU fuel helps these advanced reactors achieve higher burnups and longer cycle times than current LWRs. However, changes to the fuel enrichment change the material requirements of their fuel cycled, and may delay new reactor deployment.

The current supply chain for LEU below $5 \%{ }^{235} \mathrm{U}$ enriches natural uranium (NU) to the required level, and there is no commercial supply chain for HALEU. The mass of uranium that can be mined and the Separative Work Unit (SWU) capacity available to enrich it limits the mass of enriched uranium that can be produced. Understanding

\footnotetext{
*e-mail: amandab7@illinois.edu
}

the transition to HALEU-fueled reactors will inform the material requirements to meet electricity demands and the potential rate of reactor deployment.

In 2011 the U.S. Department of Energy Office of Nuclear Energy (DOE-NE) commissioned a Nuclear Fuel Cycle Evaluation and Screening (E\&S) [1] to compare fuel cycle options at equilibrium to determine their advantages and disadvantages. The fuel cycle options were compared based on 9 high-level performance metrics, such as resource utilization and environmental impact. Each of the fuel cycle options included in the E\&S fall into one of 40 different evaluation groups (EGs), defined by fuel characteristics such as the fuel type, neutron spectrum, and the inclusion of spent fuel recycling.

One of the EGs, EG02 - "Once-through using enrichedU fuel to high burnup in thermal or fast critical reactors" - evaluated the metrics of a future fuel cycle with a High Temperature Gas-Cooled Reactor (HTGR) using uranium fuel enriched to $15.5 \%$ and achieving $120 \mathrm{GWd} / \mathrm{t}$ burnup. The E\&S found that this fuel cycle requires about $20,000 \mathrm{t}$ of NU and about $600 \mathrm{t}$ of fuel at $15.5 \%$ enrichment each year to produce 100 GWe-yr at equilibrium. Almost $19,000 \mathrm{t}$ of $\mathrm{NU}$ and about $2000 \mathrm{t}$ of uranium fuel at $4.21 \%$ enrichment are required in EG01 - "Once-through using 
enriched-U fuel in thermal critical reactors" - which models the continued use of current LWRs. This shows an increase in $\mathrm{NU}$ and a decrease in enriched uranium mass are needed to deploy reactors using HALEU. A similar effect was observed by increasing the enrichment of fuel in a Pressurized Water Reactor (PWR) from $4 \%$ to $7 \%$ [2], and in a LWR Small Modular Reactor (SMR) of Russian origin [3].

Based on prior work, we expect increasing the enrichment level of uranium fuel to increase the material requirements at the front end of the fuel cycle. However, the exact change in requirements depends on the type of reactor, enrichment level, and transition scenario. Modeling the transition to any future reactor design can quantify the material requirements of the transition and help us understand if the current supply chain is sufficient to meet them. Comparing the material requirements of each transition scenario will reveal any advantages or disadvantages of a given transition scenario.

This work aims to quantify the material resource requirements at the front end of the transition to different types of HALEU-fueled advanced reactors, assuming that NU will be enriched to produce fuel for LWRs and HALEU-fueled reactors. Metrics of interest include the deployment schedule of HALEU-fueled reactors, mass of enriched uranium, and the SWU capacity required to enrich uranium for each scenario.

\section{Methodology}

This work simulates multiple transition scenarios to advanced reactors requiring HALEU for fuel, then quantifies and compares the front-end material requirements of each scenario. Five different fuel cycle scenarios are modeled using Cyclus [4]; an open-source, agent-based fuel cycle simulator. Cyclus defines facilities, institutions, and regions as agents within a fuel cycle simulation and models material transactions between agents according to a dynamic resource exchange.

The first scenario models only the LWRs deployed in the United States and provides a reference for comparison of the material requirements of the transitions. The next two scenarios model no-growth transitions to the Ultra Safe Nuclear Corporation (USNC) Micro Modular Reactor (MMR) or the X-Energy Xe-100 reactor. The last two scenarios model a $1 \%$ annual growth transition to the USNC MMR or the X-Energy Xe-100 reactor. Table 1 summarizes each of the scenarios.

The International Atomic Energy Agency (IAEA) Power Reactor Information System (PRIS) database [5] provided the grid connection date and power level of each LWR, and the decommission date for any reactor closed before December 2020. Reactor lifetimes assume 60 years of operation after the grid connection date for any LWR still in operation in December 2020. The simulations do not consider research or experimental reactors, and therefore only include reactors with power levels above 400 MWe. The mass of fuel in the LWR reactor cores, including the mass required for each refueling, was obtained
Table 1. Summary of the fuel cycle scenarios

\begin{tabular}{lll}
\hline $\begin{array}{l}\text { Scenario } \\
\text { Number }\end{array}$ & Reactors Present & Growth \\
\hline 1 & LWRs & N/A \\
2 & LWRs and USNC MMR & None \\
3 & LWRs and X-energy Xe-100 reactor & None \\
4 & LWRs and USNC MMR & $1 \%$ \\
5 & LWRs and X-energy Xe-100 reactor & $1 \%$ \\
\hline
\end{tabular}

from supplementary sources [6,7]. All LWRs are assumed to have an 18 month cycle length.

A variety of open-source, non-proprietary documents supplied data about the advanced reactors [8-12]. This includes the power output, enrichment level, fuel form, reactor lifetime, fuel burnup, mass of uranium in the core, and cycle time, shown in Table 2. The uranium mass in the core was calculated based on information found in public, non-proprietary sources.

Knowing a reactor's end of life (EOL) burnup, power output, and cycle length allows for calculating its initial load of fissile materials. For the MMR, considering a burnup of $42.7 \mathrm{MWd} / \mathrm{kgU}$ [9], a power output of 40 MWth, and a cycle length of 2042 effective full power days (EFPD) [10] results in the batch mass shown in Table 2. The following simulations assume that this value remains constant for the power output and cycle length specified in the same table.

The mass of uranium needed for the fresh Tristructural Isotropic (TRISO) based fuel pebbles for the Xe-100 reactor was found by calculating the total volume of uranium oxycarbide (UCO) TRISO kernels in a fuel pebble, then multiplying by the number of pebbles in the Xe-100 core [11]. Then, the total volume in the core is multiplied by the density of UCO and the mass fraction of uranium.

The Xe-100 reactor has a greater power output, requires a higher enrichment level, and has a longer lifetime than the MMR. However, the MMR has a longer cycle time than the Xe-100 because it does not require refueling once it is operational. Both advanced reactors require fuel comprised of TRISO particles, but in different forms. Refueling of the Xe-100 reactor is modeled as a replacement of $1 / 7$ of the core mass every six months.

Each of the simulations model reactor deployment and operation from 1965 to 2090, with the transition to advanced reactors beginning in 2025 for the applicable scenarios. Therefore, in the no growth scenarios the power demand remains constant at the power produced in 2025. A linear (for no growth) or exponential (for $1 \%$ growth) equation models the energy demand of each transition scenario. A Cycamore GrowthRegion archetype [4] defines the energy demand of the scenario and determines if additional facilities are required to meet the demand. The LWRs are deployed using the Cycamore DeployManagerInst archetype, and the advanced reactors are deployed as needed to meet the prescribed power demand of the scenario using the Cycamore ManagerInst archetype [4]. The Cycamore DeployManagerInst deploys facilities according to a manually defined schedule, with 
Table 2. Advanced reactor design specifications.

\begin{tabular}{lll}
\hline Design Criteria & USNC MMR [8] & X-Energy Xe-100 [11,12] \\
\hline Reactor type & Modular HTGR & Modular HTGR \\
Power Output (MWe) & 10 & 75 \\
Enrichment $\left(\%{ }^{235} \mathrm{U}\right)$ & 13 & 15.5 \\
Cycle Length (years) & 20 & online refueling \\
Fuel form & TRISO compacts & TRISO pebbles \\
Reactor Lifetime (yrs) & 20 & 60 \\
Mass of uranium per refu- & 1912.9 & 223.87 \\
eling (kg) & & \\
Burnup (MWd $/ \mathrm{kg} \mathrm{U})$ & 42.7 & 163 \\
\hline
\end{tabular}

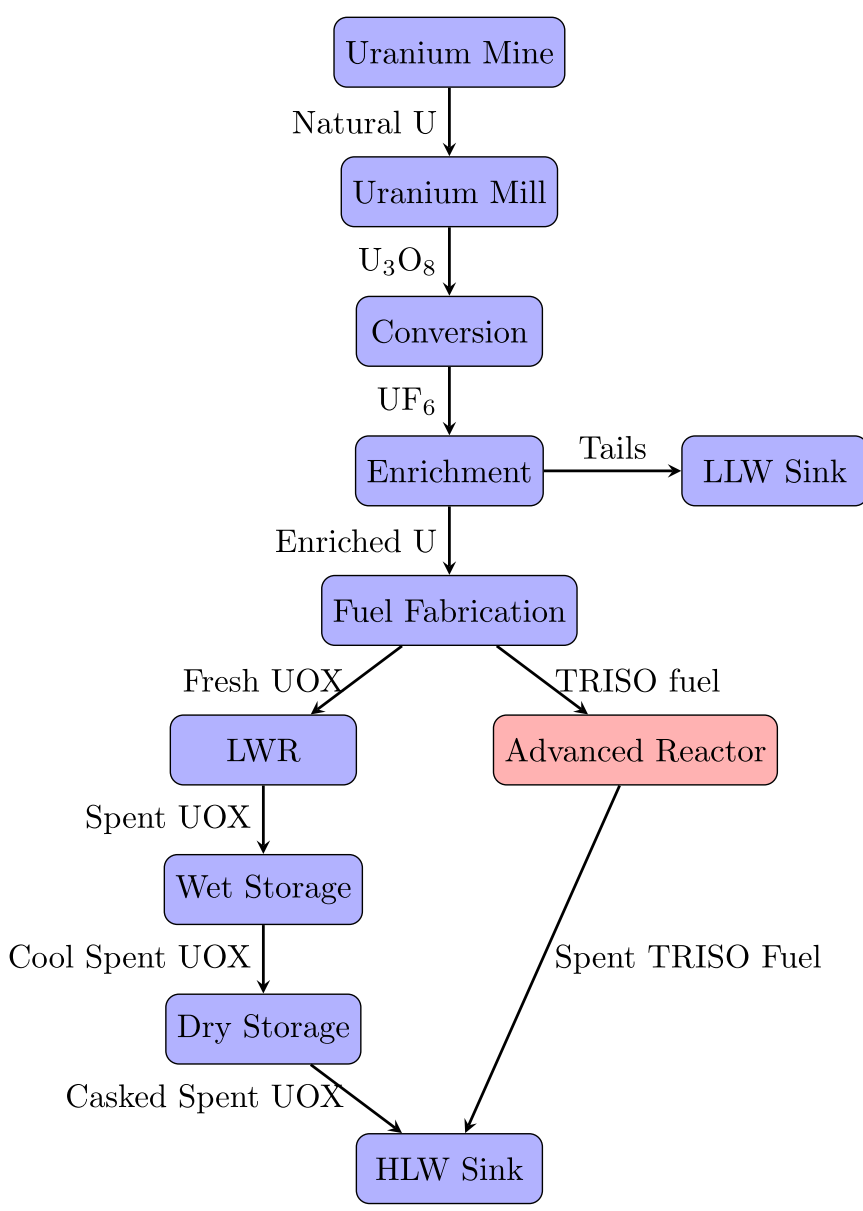

Fig. 1. Fuel cycle facilities and material flow between facilities. Facilities in red are deployed in the transition scenarios.

the Cycamore GrowthRegion recognizing each facility deployed and how it contributes to the specified capacity.

The scenarios model the fuel cycle from the uranium mine to final disposal in the high level waste (HLW) Sink. Figure 1 shows the fuel cycle modeled in each simulation. Scenario 1 includes only the facilities in blue. All facilities are used in Scenarios 2-5, and the facility in red is the advanced reactor deployed in the scenario. Although the simulations model the back end of the fuel cycle, quantifying any waste is considered outside the scope of this work.

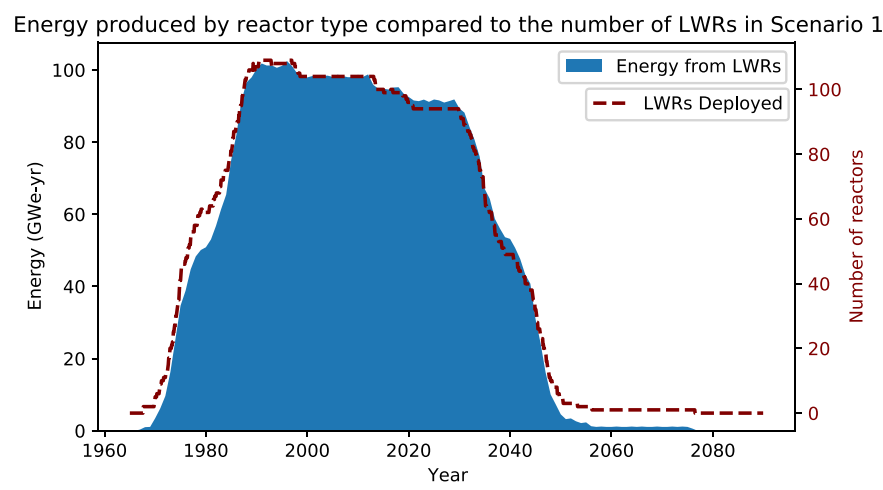

Fig. 2. Energy supplied by LWRs compared to the number of LWRs deployed in Scenario 1.

Recipes define the composition of the materials shown in Figure 1. Yacout et al. [13] supplied recipes for spent and fresh LWR fuel assuming a $51 \mathrm{MWd} / \mathrm{kg}$-U burnup. All other recipes capture the necessary uranium isotopic ratios, but do not include other elements. This work does not include neutronic or depletion simulations to determine any material compositions. The enrichment facility assumes the feed material is NU, and the tails assay is $0.2 \%$.

\section{Results}

The results presented for each scenario include the energy produced, reactor deployment schedule, enriched uranium mass, HALEU mass, and SWU capacity required as a function of time.

\subsection{Scenario 1}

The energy supplied by the LWRs and the number of LWRs deployed as a function of time are shown in Figure 2. LWRs are first deployed in August of 1967. The last LWR is deployed in June of 2016 and decommissioned in July 2076. The maximum number of LWRs deployed at one time is 109 . The energy produced by the LWRs follows the number of reactors deployed. The maximum energy produced by the LWRs is 102.46 GWe-y, and they produce 91.82 GWe-y in 2025.

Next, Figure 3 shows the mass of enriched uranium sent to the LWRs at each time step. The LWRs are defined to 


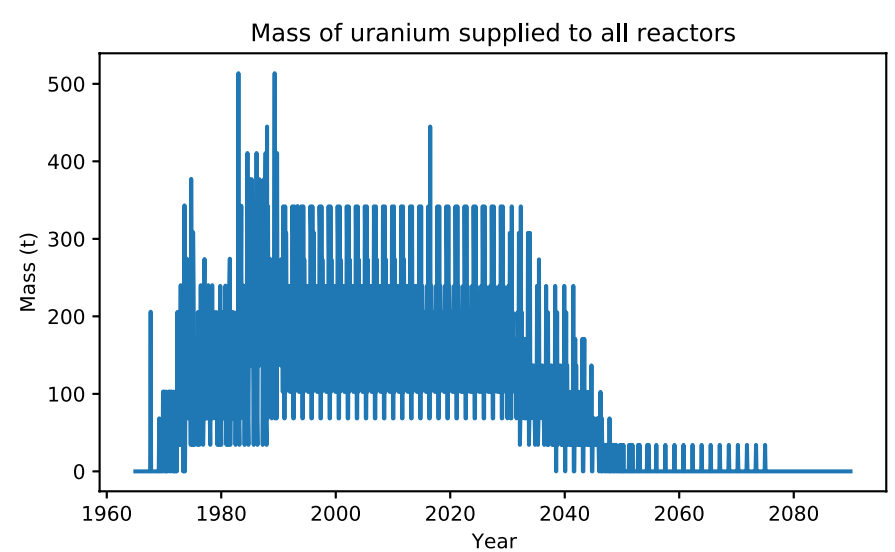

Fig. 3. Mass of enriched uranium sent to reactors in Scenario 1.

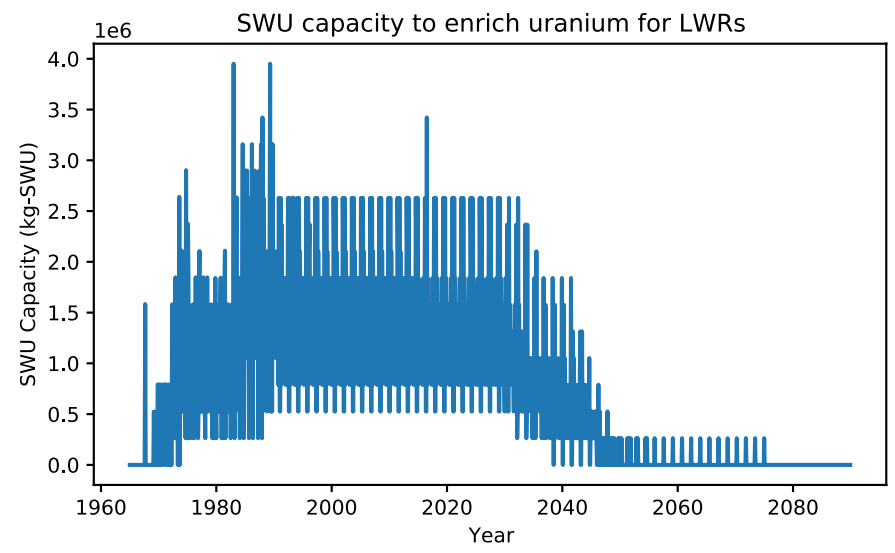

Fig. 4. Total SWU capacity required to produce fuel sent to the reactors at each time step in Scenario 1.

have an 18 month cycle length, with a third of the uranium mass replaced each refueling outage. New reactors in the simulations are deployed with an entire core of uranium, leading to increases in the mass of uranium sent to the reactors at a single time step, such as in 1983 and 2016. An average of $96.2 \mathrm{tU} /$ month and a maximum of $513.7 \mathrm{tU}$ are sent to the LWRs. Prior to 2025, the average mass of enriched uranium sent to the LWRs is $157.6 \mathrm{tU} / \mathrm{month}$. A total of 30,635.0 tU are sent to LWRs after 2025 in this scenario.

Finally, Figure 4 shows the SWU capacity to produce fuel for the scenario. The SWU capacity required as a function of time follows the mass of uranium sent to the reactors, because the SWU is calculated based on those transactions. This scenario requires an average of $0.74 \times 10^{6} \mathrm{~kg}-\mathrm{SWU} / \mathrm{month}$ and a maximum of $3.95 \times$ $10^{6} \mathrm{~kg}$-SWU. Prior to 2025, this scenario requires an average of $1.21 \times 10^{6} \mathrm{~kg}$-SWU/month to enrich the uranium sent to the LWRs. After 2025, an average of $0.302 \times 10^{6}$ $\mathrm{kg}-\mathrm{SWU}$ is required to enrich the uranium sent to the LWRs. A total of $11.1 \times 10^{8} \mathrm{~kg}$-SWU are required to enrich uranium for the reactors in this scenario, and a total of $2.36 \times 10^{8} \mathrm{~kg}$-SWU is required to enrich uranium sent to LWRs after 2025.

The other scenarios in this work apply the deployment and decommissioning schedule of the LWRs in this

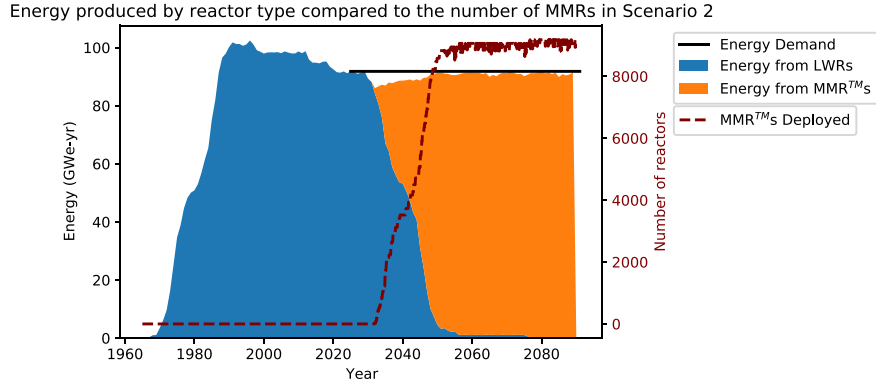

Fig. 5. Energy supplied by each type of reactor compared to the number of MMRs deployed in Scenario 2.

scenario, and therefore the material requirements of the transition scenarios prior to 2025 are the same as those of this scenario.

\subsection{Scenario 2}

The energy produced by each type of reactor, the transition energy demand, and the deployment schedule of the MMRs in Scenario 2 are shown in Figure 5. The first MMRs are deployed in October 2031, and the maximum number deployed at one time is 9,182 . This is about two orders of magnitude greater than the LWRs deployed in 2025.

Once the transition begins in 2025, the energy demand of the scenario is not met every year. The first of energy deficit is between 2030-2050, with a maximum deficit of 5.7855 GWe-y in 2032. Other periods in which the energy demand is not met correspond to the decommissioning of MMRs at the end of their lifetime and the deployment of new reactors, such as from 2062-2069. The deployment of MMRs in 2031 contributes to the inability to meet the energy demand of the scenario between 20302050 , because the energy produced by LWRs decreases to 89.35 GWe-y in 2030, despite a demand of 91.82 GWe-y, before the Cycamore ManagerInst deploys MMRs. Therefore, the institution deploys the reactors in a reactionary fashion to past energy production, as opposed to in response to forecasted energy production. This deployment scheme will likely lead to an underestimation of fuel requirements, because the reactors are deployed at a later time than required by the energy demand.

Next, Figure 6 shows the mass of enriched uranium sent to all reactors in the scenario and just to the MMRs. The MMRs do not require refueling during their lifetime, so uranium is sent to these reactors only when they are deployed. Thus, there are periods of uranuim demand corresponding the MMR deployment, separated by periods of low or no demand. All of the reactors receive an average of $104.94 \mathrm{tU} /$ month and a maximum of $781.41 \mathrm{tU}$ after 2025 . This average is less than the average mass of enriched uranium sent to the LWRs in Scenario 1, but the maximum sent to the MMRs exceeds the maximum mass of enriched uranium sent to LWRs in Scenario 1 by $267.71 \mathrm{tU}$. The MMRs receive an average of $73.12 \mathrm{tU} /$ month and a maximum of $719.25 \mathrm{tU}$ once they are deployed in 2031. The metrics for the LWRs after 2025 are the same as those in 


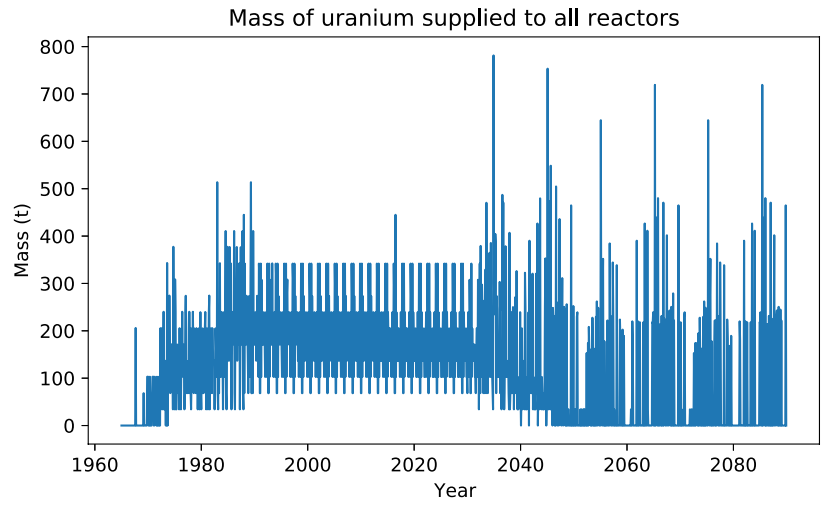

(a) Mass of enriched uranium sent to all reactors.

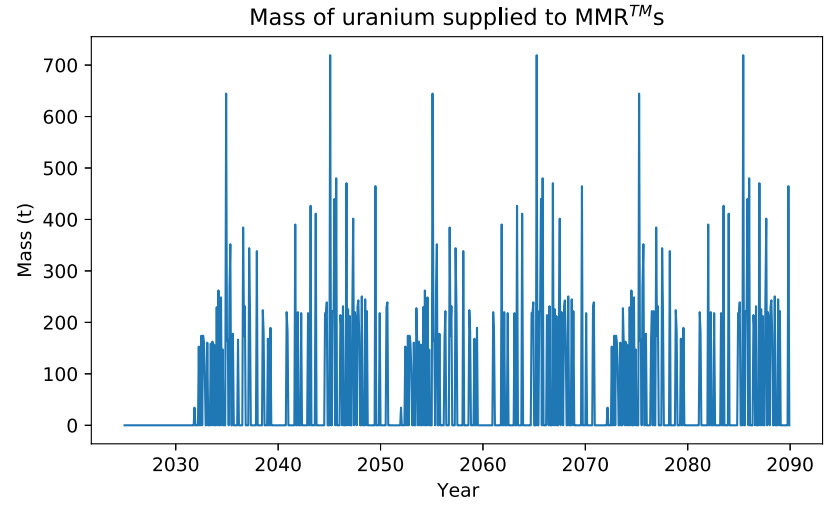

(b) Mass of enriched uranium sent to $\mathrm{MMR}^{\mathrm{TM}} \mathrm{S}$.

Fig. 6. Enriched uranium mass sent to reactors in Scenario 2.

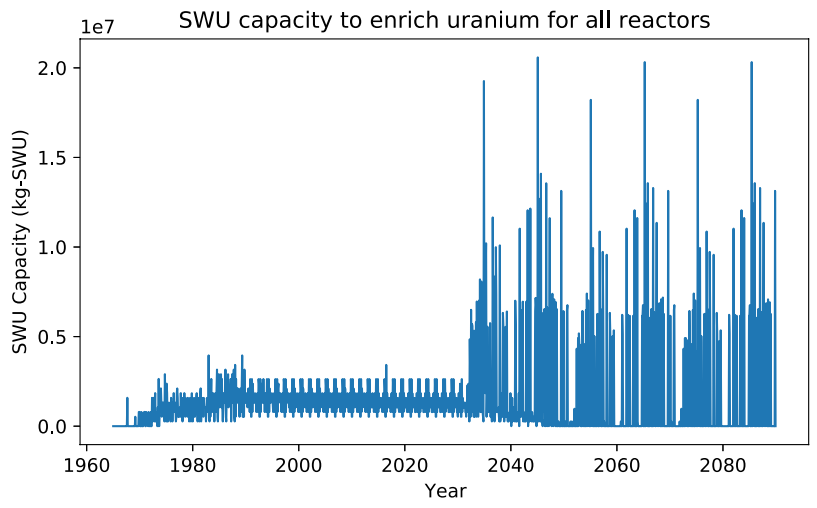

(a) SWU required to enrich uranium sent to all reactors at each time step.

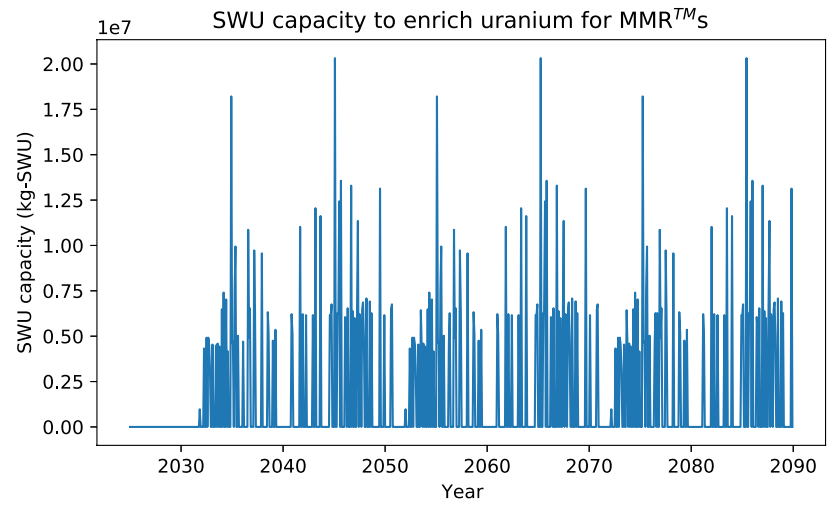

(b) SWU required to enrich uranium sent to $\mathrm{MMR}^{\mathrm{TM}} \mathrm{S}$ at each time step.

Fig. 7. SWU required to enrich natural uranium in Scenario 2.

Scenario 1, because the LWR deployment and decommissioning scheme is the same in both scenarios. The average mass of enriched uranium sent to the MMRs is less than the average mass of uranium sent to the LWRs prior to 2025. This is despite a greater maximum and multiple peaks larger than the average mass sent to the LWRs. The smaller average is because of the lack of refueling and the multiple time steps when additional MMRs are not deployed. The average mass of uranium required to fuel the MMRs is more than what is required by EG 02 [1], despite producing less power. After 2025, all of the reactors receive a total of $81,747.7 \mathrm{tU}$. The MMRs receive a total of $51,112.7 \mathrm{tU}$. These totals show that most of the uranium produced after 2025 is for use in the advanced reactors, which is consistent with the reactor deployment and decommissioning schedule.

Figure 7 shows the SWU capacity needed to enrich uranium for all reactors in the scenario, and to enrich uranium for just the MMRs. The MMR fleet requires a greater SWU capacity than the LWR fleet prior to 2025 because the MMRs require uranium at a higher enrichment level. Enriching uranium for the MMRs requires an average of

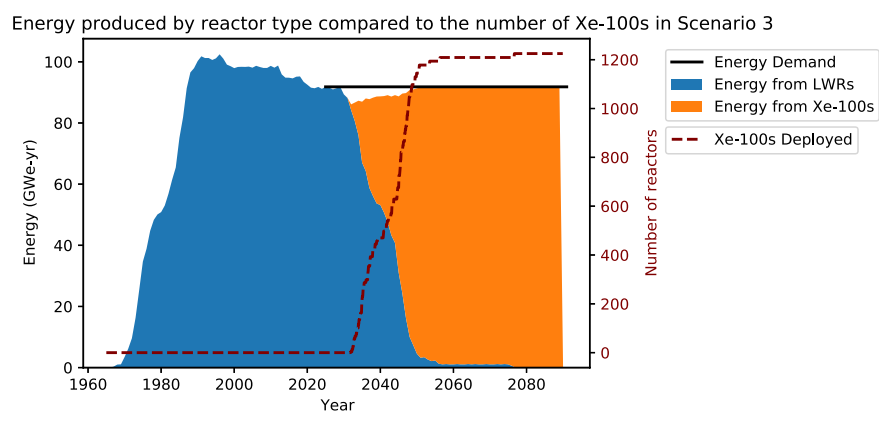

Fig. 8. Energy supplied by each type of reactor compared to the number of Xe-100s deployed in Scenario 3.

$2.07 \times 10^{6} \mathrm{~kg}-\mathrm{SWU} / \mathrm{month}$ and a maximum of $20.3 \times 10^{6}$ $\mathrm{kg}-\mathrm{SWU}$. These values are both more than the average and maximum SWU capacity needed to enrich uranium for the LWRs prior to 2025. Enriching uranium for all reactors after 2025 requires a total of $16.8 \times 10^{8} \mathrm{~kg}-\mathrm{SWU}$. Enriching uranium for just the MMRs requires $14.4 \times 10^{8}$ kg-SWU. 


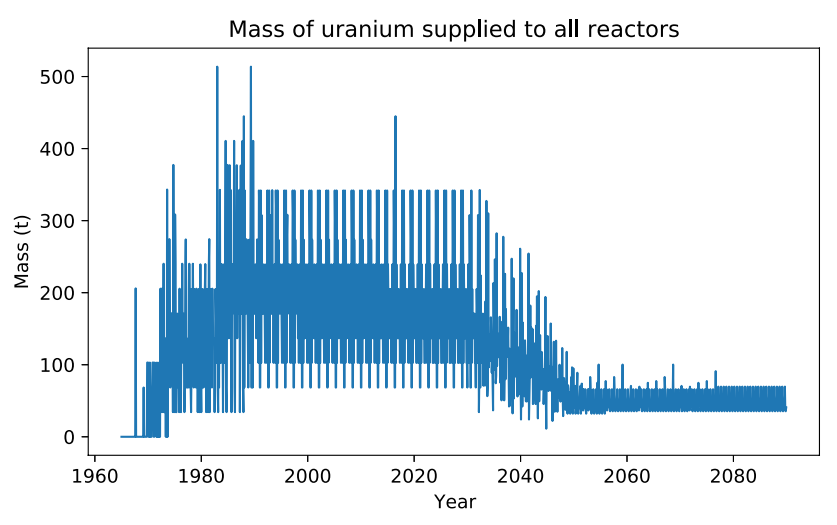

(a) Mass of enriched uranium sent to all reactors.

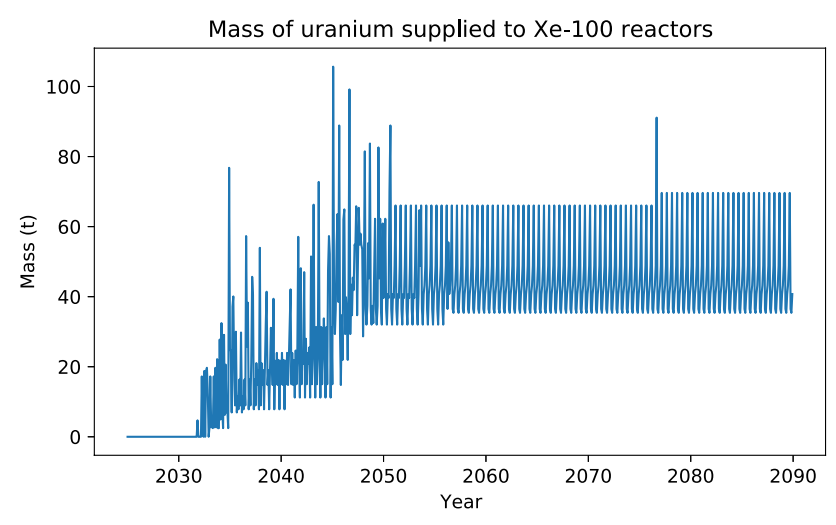

(b) Mass of enriched uranium sent to Xe-100s.

Fig. 9. Enriched uranium mass sent to reactors in Scenario 3.

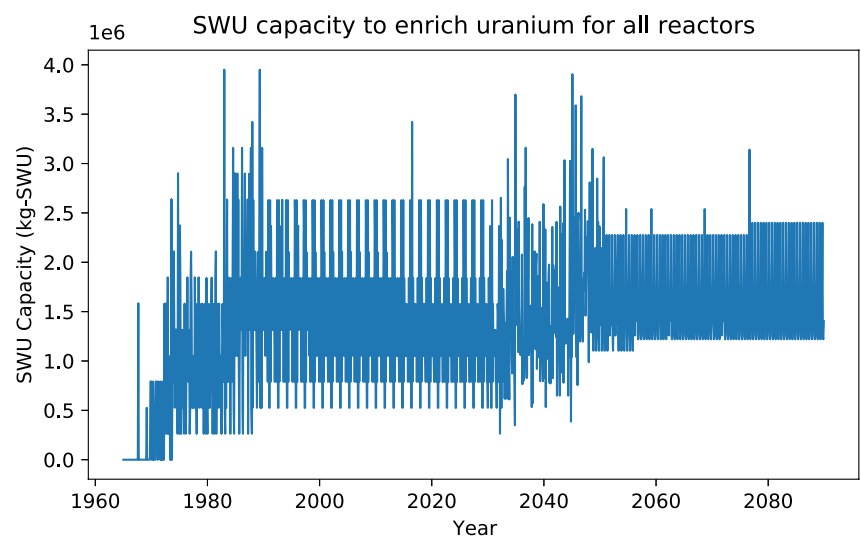

(a) SWU required to enrich uranium sent to all reactors.

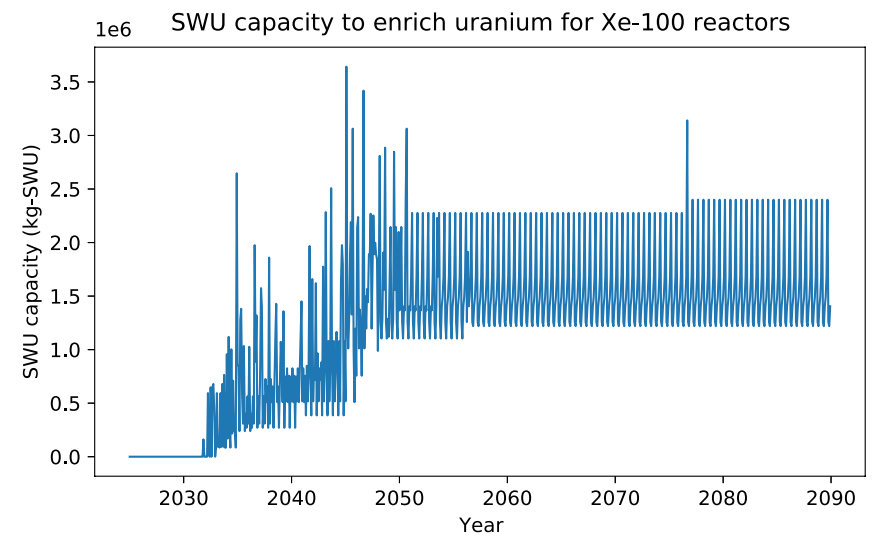

(b) SWU required to enrich uranium sent to Xe-100s.

Fig. 10. SWU required to enrich natural uranium in Scenario 3.

\subsection{Scenario 3}

For Scenario 3, Figure 8 shows the number of Xe-100 reactors deployed, the energy produced by each reactor type, and the energy demand. Xe-100 reactors are deployed in October 2031, which is the same as when MMRs are deployed in Scenario 2. Scenario 3 deploys a maximum of $1,225 \mathrm{Xe}-100$ reactors, one-ninth the number of MMRs in Scenerio 2.

Scenario 3 exhibits the same deficit between the energy produced and demand between 2030-2050 that was observed in Scenario 2. However, the energy produced does not differ from the energy demand by more than 1 GWe-yr after 2050 because the Xe-100 reactors have a longer lifetime and the simulation does not include the replacement of the Xe-100s. After 2050, the maximum difference between the energy produced and demand is 0.057 GWe-y.

Comparing the mass of uranium sent to all of the reactors and just the Xe-100 reactors, shown in Figure 9, the $\mathrm{Xe}-100$ reactors require less fuel at each time step than what is sent to the LWRs, despite there being more Xe-100 reactors than LWRs. An average of $74.98 \mathrm{tU} /$ month and a maximum of $342.58 \mathrm{tU}$ are sent to all of the reactors in this scenario starting in 2025. An average of $39.74 \mathrm{tU} /$ month and a maximum of $105.67 \mathrm{tU}$ are sent to the Xe-100 reactors in this scenario. Both metrics are less than the average and maximum masses of enriched uranium in Scenario 1, and the HALEU mass sent to the MMRs in Scenario 2. The average mass required to fuel the Xe-100 reactors is less than the fuel mass required by the HTGRs in EG 02 [1]. A total of 58,410.1 tU and 27,775.1 tU are sent to all reactors after 2025 and the advanced reactors in the scenario, respectively, showing that this transition scenario requires less uranium than Scenario 2.

Figure 10 shows the SWU capacity needed to enrich uranium for all of the reactors in the scenario, and for the uranium sent to just the Xe-100 reactors. The average SWU capacity needed to enrich uranium in Scenario 3 after 2025 is similar to the capacity to enrich uranium prior to 2025, despite the increased enrichment level of uranium sent to the $\mathrm{Xe}-100$ reactors. This is because the Xe-100 reactors receive a smaller average mass of enriched uranium at each time step. Enriching uranium for the Xe-100 reactors requires an average of $1.37 \times 10^{6}$ $\mathrm{kg}-\mathrm{SWU} / \mathrm{month}$ and a maximum of $3.64 \times 10^{6} \mathrm{~kg}-\mathrm{SWU}$. 


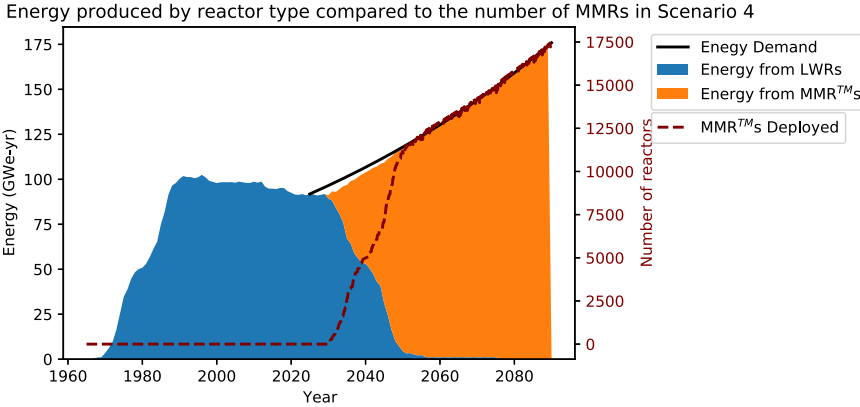

Fig. 11. Energy supplied by each type of reactor compared to the number of MMRs deployed in Scenario 4.

A total of $11.9 \times 10^{8} \mathrm{~kg}-\mathrm{SWU}$ and $9.57 \times 10^{8} \mathrm{~kg}-\mathrm{SWU}$ are required to enrich uranium for all reactors after 2025 and the advanced reactors in the scenario, respectively.

\subsection{Scenario 4}

Figure 11 shows the number of MMRs deployed, the energy produced by each type of reactor, and the energy demand of this scenario with $1 \%$ growth. MMRs are deployed in January 2030, and the maximum number of MMRs is 17,496 .

There is a deficit between the energy produced and demand from 2026-2046, with a maximum difference of 4.51 GWe-y in 2032. There are no other times in which the energy demand is not met by a significant amount (more than 1 GWe-y), including when the MMRs are decommissioned. After 2047 electricity is generally produced in surplus, up to 1.64 GWe-y.

Figure 12 shows the mass of enriched uranium sent to all the reactors in the scenario, and to just the MMRs in the scenario. An average of $144.36 \mathrm{tU} /$ month and a maximum of $796.71 \mathrm{tU}$ are sent to all the reactors starting in 2025 in this scenario. An average of $113.64 \mathrm{tU} /$ month and a maximum of $782.38 \mathrm{tU}$ are sent to just the MMRs in the scenario once they are deployed. The mass of HALEU required by the MMRs in this scenario is more than in Scenario 2 due to the increased energy demand and the additional MMRs deployed. The average mass of HALEU sent to the MMRs in this scenario is slightly less than the average mass sent to the LWRs. A total of 112,453.6 $\mathrm{tU}$ and 81,818.6 tU are required for all of the reactors after 2025 and the advanced reactors in the scenario, respectively.

Figure 13 shows the SWU capacity required to enrich uranium for all the reactors in the scenario, and only for the MMRs. For the same reasons described for Scenario 2, the SWU capacity required to enrich uranium for the MMRs is greater than the capacity needed to enrich uranium for the LWRs. An average of $3.21 \times 10^{6}$ $\mathrm{kg}-\mathrm{SWU} / \mathrm{month}$ and a maximum of $22.1 \times 10^{6} \mathrm{~kg}-\mathrm{SWU}$ are required to enrich the uranium that is sent to MMRs. These values are larger than the SWU capacity required to enrich uranium for the MMRs in Scenario 2. The average SWU capacity to enrich uranium for the MMRs is slightly greater than the average SWU capacity required to enrich uranium for the LWRs before 2025. A total of $25.5 \times 10^{8}$ $\mathrm{kg}-\mathrm{SWU}$ and $23.1 \times 10^{8} \mathrm{~kg}-\mathrm{SWU}$ are required to enrich uranium for all reactors after 2025 and the advanced reactors in the scenario, respectively.

\subsection{Scenario 5}

Figure 14 shows the number of Xe-100 reactors, the energy produced by each type of reactor, and the energy demand of the scenario. The Xe-100 reactors are deployed in January 2030, the same time MMRs are deployed in Scenario 4. The maximum number of Xe-100 reactors deployed in the scenario is 2,339 , which is about 15,000 reactors fewer than the MMRs required to meet the same energy demand.

The energy produced is less than the energy demand from 2026-2046, the same deficit that is observed in Scenario 4. After this initial difference, there are no further significant (more than 1 GWe-y) differences between the energy produced and demand. For most years after 2046 there is a surplus of energy, up to 1.64 GWe-y.

Figure 15 shows the mass of enriched uranium sent to all of the reactors in the scenario and the HALEU mass sent just to the $\mathrm{Xe}-100$ reactors. There is an increase in the mass of HALEU sent to the Xe-100 reactors as time goes on, but this mass is still low compared to the mass of enriched uranium sent to the LWRs in the scenario. An average of $95.46 \mathrm{tU} /$ month and a maximum of $347.28 \mathrm{tU}$ are sent to all of the reactors in this scenario after 2025. These values are both less than the uranium mass sent to the LWRs prior to 2025. An average of $60.73 \mathrm{tU} /$ month and a maximum of $123.80 \mathrm{tU}$ are sent to the Xe-100 reactors. These metrics are all less than what is observed for fueling the MMRs in Scenario 4. A total of $74,361.76 \mathrm{tU}$ and $43,726.74 \mathrm{tU}$ are required to fuel all reactors after 2025 and the advanced reactors in the scenario, respectively.

Finally, Figure 16 shows the SWU capacity required to enrich the uranium sent to all of the reactors, and just the Xe-100 reactors. The SWU capacity needed to enrich uranium for the Xe-100 reactors starts out at a similar amount as the LWRs, but increases with the energy demand and number of reacotrs. The SWU capacity required to enrich uranium for the Xe-100 reactors becomes greater than the capacity required to enrich uranium for LWRs, despite the Xe-100 reactors requiring a lesser mass of uranium. This is because the Xe-100 requires fuel at a greater enrichment level. An average of $2.09 \times 10^{6} \mathrm{~kg}-\mathrm{SWU} / \mathrm{month}$ and a maximum of $4.26 \times 10^{6}$ $\mathrm{kg}-\mathrm{SWU}$ are required to enrich the uranium sent to the Xe-100 reactors. The average SWU capacity required to enrich uranium for the Xe-100 reactors is lower than the average capacity needed to enrich uranium for the MMRs in Scenario 4, but the maximum capacity required for this scenario is much less than in Scenario 4. These values are slightly greater than what is observed to enrich uranium for the LWRs prior to 2025 . A total of $17.4 \times 10^{8} \mathrm{~kg}-\mathrm{SWU}$ and $15.1 \times 10^{8} \mathrm{~kg}-\mathrm{SWU}$ are required to enrich uranium for all reactors after 2025 and the advanced reactors in the scenario. 


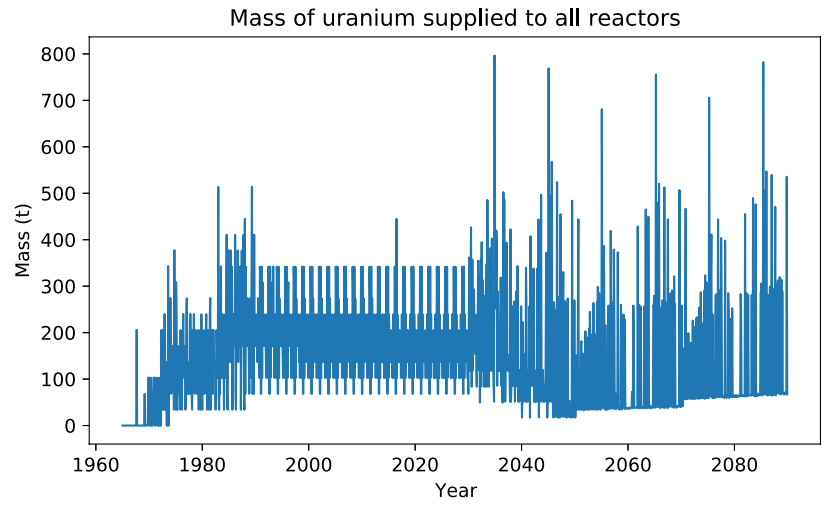

(a) Mass of enriched uranium sent to all reactors.

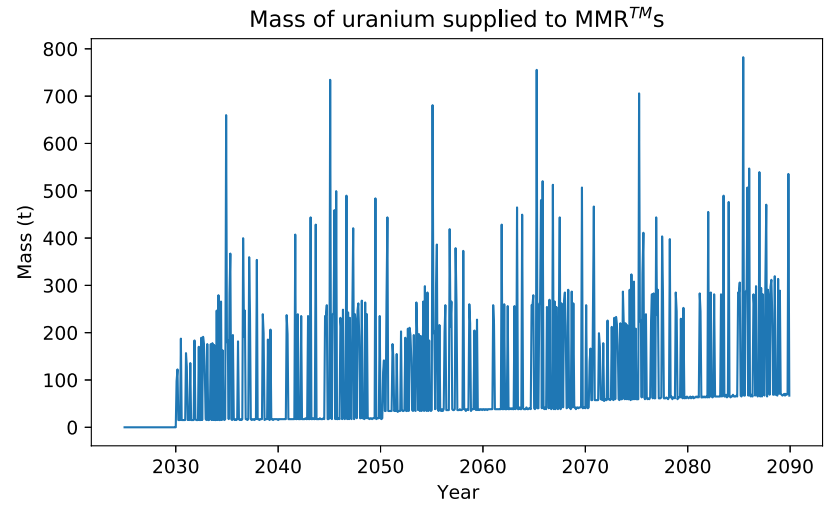

(b) Mass of enriched uranium sent to $\mathrm{MMR}^{\mathrm{TM}} \mathrm{s}$.

Fig. 12. Enriched uranium mass sent to reactors in Scenario 4.

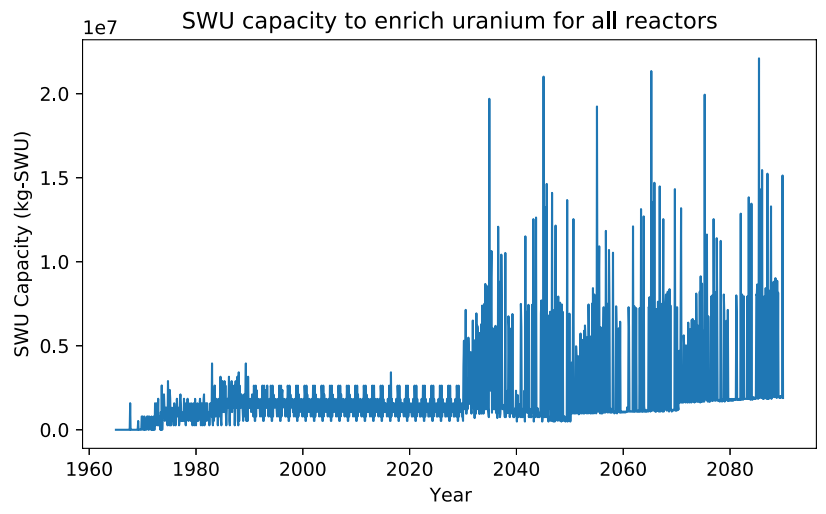

(a) SWU required to enrich uranium sent to all reactors.

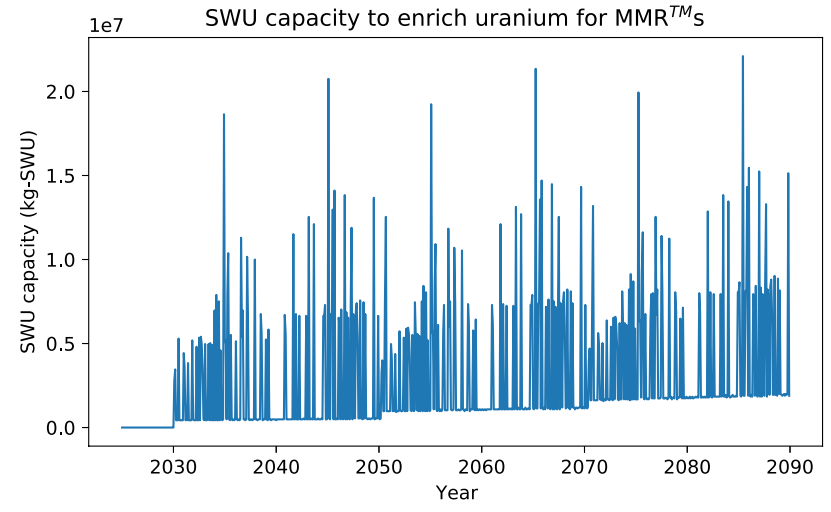

(b) SWU required to enrich uranium sent to $\mathrm{MMR}^{\mathrm{TM}} \mathrm{s}$.

Fig. 13. SWU required to enrich natural uranium in Scenario 4.

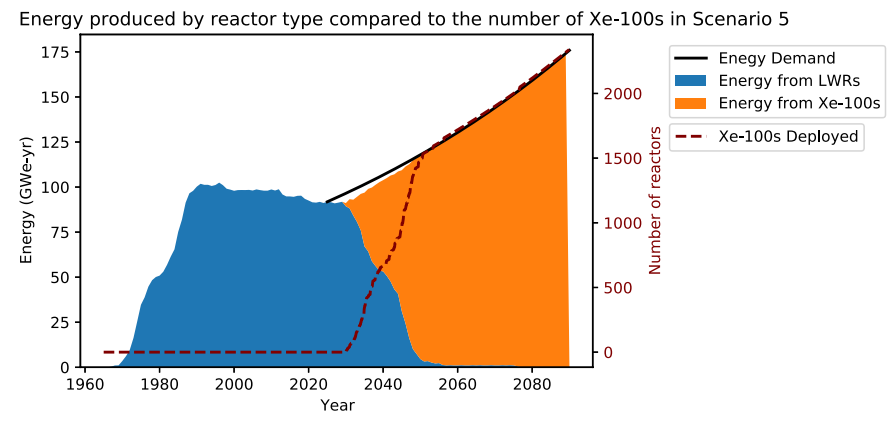

Fig. 14. Energy supplied by each type of reactor compared to the number of Xe-100s deployed in Scenario 5.

\subsection{Scenario comparisons}

The mass of uranium sent to all reactors for each scenario and to just the advanced reactors is shown in Figure 17. Fueling the Xe-100 reactors in Scenarios 3 and 5 requires less uranium than fueling the LWRs prior to 2025 at each time step. Fueling the MMRs in Scenarios 2 and 4 requires the most uranium at any single time step, but the average uranium mass is less than what is required to fuel the
LWRs prior to 2025. This is because of multiple time steps in which no or a small mass (less than $20 \mathrm{tU}$ ) of uranium is sent to MMRs, which offset the timesteps that require a large mass of uranium (more than $200 \mathrm{tU}$ ) are sent to the MMRs.

Comparing the cumulative total mass of enriched uranium required in each scenario, Figure 18, deploying the MMR requires more uranium than deploying the Xe-100 reactor for the same transition scenario. Figure 18 also shows that deploying the MMR in a no growth transition scenario requires more uranium than deploying Xe-100 reactors in a $1 \%$ growth transition for the time frame modeled. Table 3 summarizes the HALEU mass requirements reported for each transition scenario: the average mass sent to the advanced reactors once they are deployed, the maximum mass sent to the advanced reactors in a single time step, and the cumulative mass sent to the fleet of advanced reactors for the scenario.

Figure 19 compares the SWU capacity required to enrich uranium for all reactors and the advanced reactors in each scenario. Table 4 summarizes the SWU capacity requirements of each transition scenario: the average capacity required once the advanced reactors are 


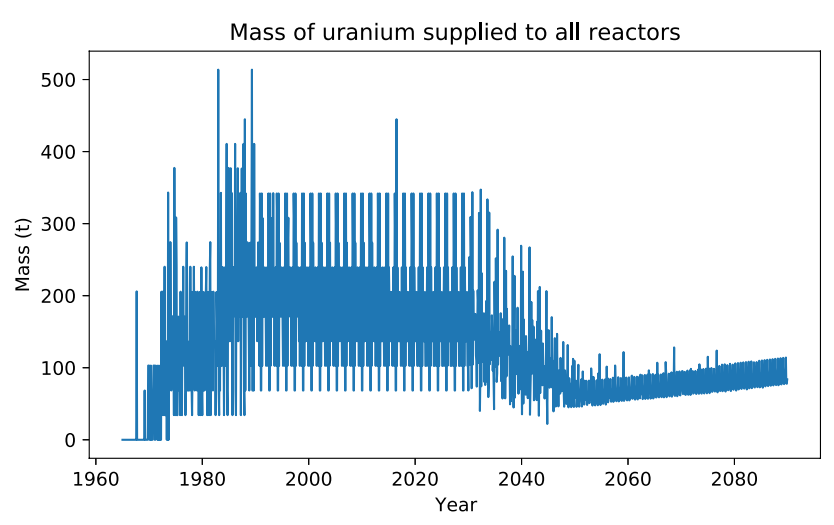

(a) Mass of enriched uranium sent to all reactors.

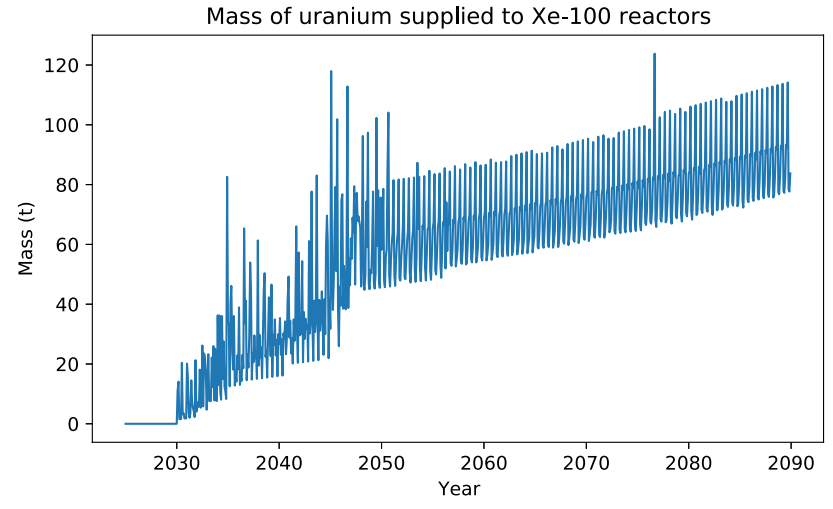

(b) Mass of enriched uranium sent to Xe-100s.

Fig. 15. Enriched uranium mass sent to reactors in Scenario 5.

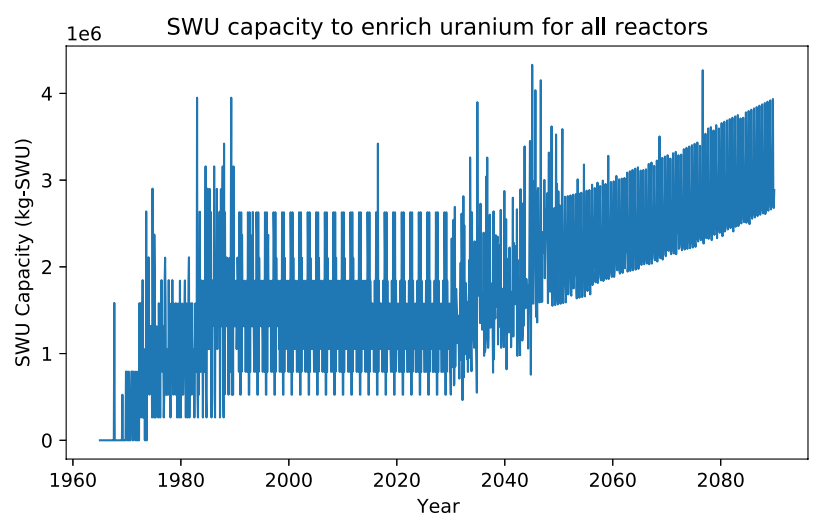

(a) SWU required to enrich uranium sent to all reactors at each time step.

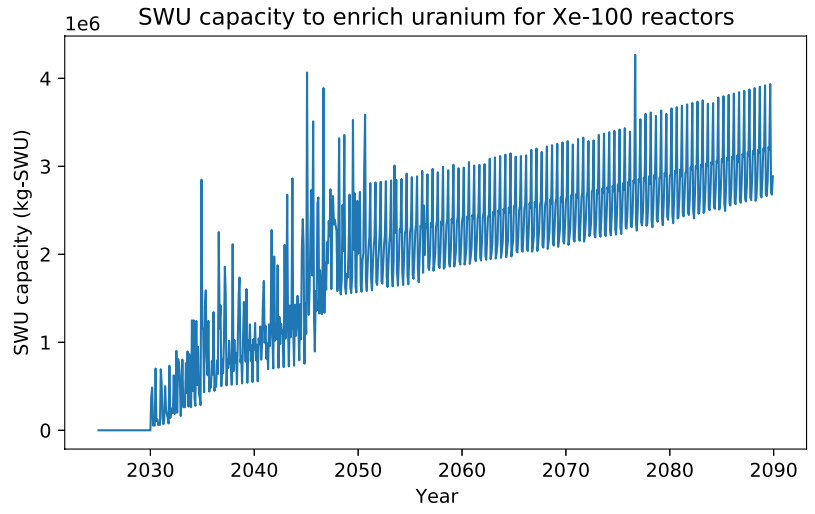

(b) SWU required to enrich uranium sent to Xe-100s at each time step.

Fig. 16. SWU required to enrich natural uranium in Scenario 5.

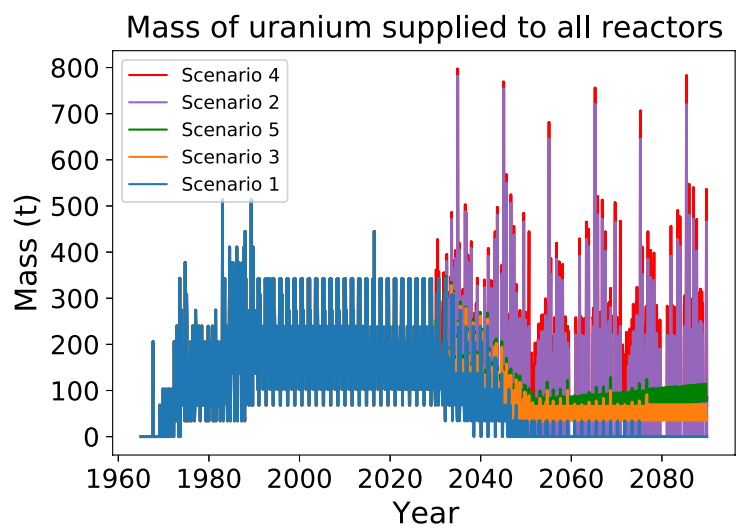

(a) Total uranium mass sent to all reactors at each time step.

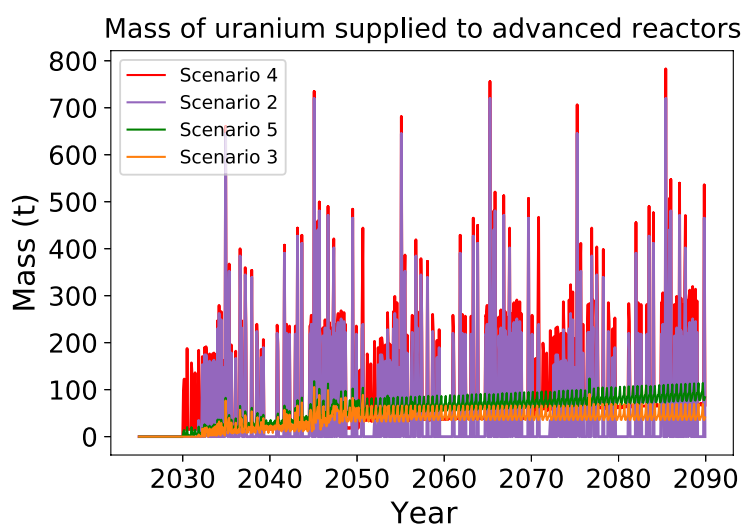

(b) Uranium mass sent to advanced reactors at each time step.

Fig. 17. Uranium mass supplied to reactors in all scenarios. 
Table 3. Summary of HALEU mass required in each transition scenario. Average values are based on when the advanced reactors are first deployed, and the maximum value is for a single time step.

\begin{tabular}{llll}
\hline Scenario & Average $(\mathrm{t})$ & Max $(\mathrm{t})$ & Cumulative $(\mathrm{t})$ \\
\hline 2 & 73.12 & 719.25 & $51,112.7$ \\
3 & 39.74 & 105.67 & $27,775.1$ \\
4 & 113.7 & 782.38 & $81,818.6$ \\
5 & 60.73 & 123.80 & $43,726.4$ \\
\hline
\end{tabular}

Table 4. Summary of SWU capacity requirements in each transition scenario. Average values are based on when the advanced reactors are first deployed, and the maximum value is for a single time step.

\begin{tabular}{llll}
\hline Scenario & Average (kg-SWU) & Max $(\mathrm{kg}-\mathrm{SWU})$ & Cumulative $(\mathrm{kg}-\mathrm{SWU})$ \\
\hline 2 & $2.07 \times 10^{6}$ & $20.3 \times 10^{6}$ & $14.4 \times 10^{8}$ \\
3 & $1.37 \times 10^{6}$ & $3.64 \times 10^{6}$ & $9.57 \times 10^{8}$ \\
4 & $3.21 \times 10^{6}$ & $22.1 \times 10^{6}$ & $23.1 \times 10^{8}$ \\
5 & $2.09 \times 10^{6}$ & $4.26 \times 10^{6}$ & $15.1 \times 10^{8}$ \\
\hline
\end{tabular}

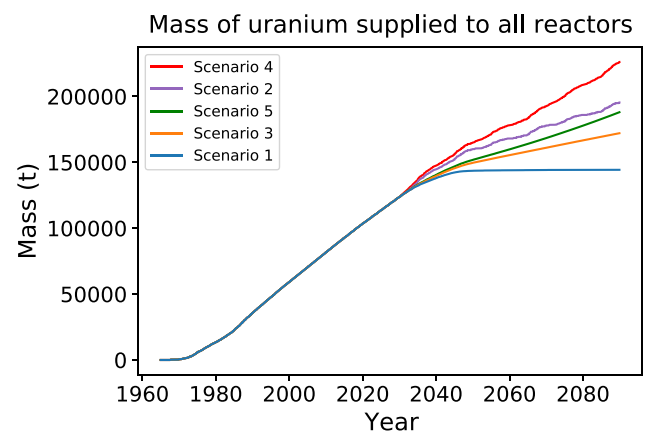

Fig. 18. Cumulative total uranium mass sent to all reactors in each scenario.

deployed, the maximum capacity needed to enrich uranium sent to the advanced reactors at a single time step, and the cumulative capacity used to enrich uranium for the fleet of advnaced reactors. The SWU capacity required to enrich uranium in Scenarios 1, 3, and 5 are similar in magnitude. Scenarios 2 and 4 appear to require a greater SWU capacity because the calculated SWU capacity is based on the mass of uranium sent to the reactors at each time step. Therefore, the values presented do not reflect the required SWU capacity of an enrichment facility.

An example of a possible facility for enriching uranium for the MMRs in Scenario 2 would have a throughput of $66 \mathrm{tU} /$ month, and a SWU capacity of $2.28 \times 10^{6}$ $\mathrm{kg}-\mathrm{SWU} /$ month. A facility of this size and capacity would be able to meet the enriched uranium demand, as Figure 20 shows. In this scenario, the enrichment facility goes online in 2025 and operates through 2090. The stored enriched uranium mass at the facility never goes below 0 , but this example does not account for any time required to fabricate the fuel before shipment to the reactor. This theoretical example shows how a constant-capacity HALEU enrichment facility can meet the enriched uranium requirements of the scenario, but further optimization of such a facility or the exploration of how other methods can be used meet the enriched uranium demand is left to future work.

\section{Conclusions}

This work simulated multiple fuel cycle scenarios to compare the material requirements of deploying different advanced reactors fueled by HALEU. Scenarios include a no-growth and a $1 \%$ growth transitions to either the USNC MMR or the X-energy Xe-100 reactor from the current fleet of U.S. LWRs. We used the current fleet of LWRs, without a transition to an advanced reactor fleet for comparison. Each of these scenarios are compared for their material requirements, specifically the number of reactors deployed, the mass of enriched uranium sent to the reactors, and the SWU capacity required to enrich natural uranium to produce the fuel needed for each scenario.

More MMRs are required than Xe-100 reactors to meet the same energy demand, because of the differences in their power output. The transition scenarios exhibit some gaps between energy production and demand, localized to the beginning of the transition scenarios, and to the replacement of MMRs as they are decommissioned. Xe-100 reactors are not decommissioned in the simulated time frame because their lifetime exceeds the time span simulated. Therefore, the energy produced and the material requirements for the replacement of Xe-100 reactors is not explored in this work.

Transitioning to the MMR requires a larger average mass and SWU capacity than transitioning to the Xe-100 reactors. Transitioning to the MMR requires a smaller average uranium mass but a greater SWU capacity than fueling LWRs prior to 2025 because the MMR requires a higher enrichment level. Fueling MMRs involves large, one-time shipments of fuel, while fueling the Xe- 100 involves small, continuous shipments of fuel because of the different refueling schemes.

\section{Future work}

One possible area of future work is extending the end date of the scenarios to 2125 to investigate how replacing 


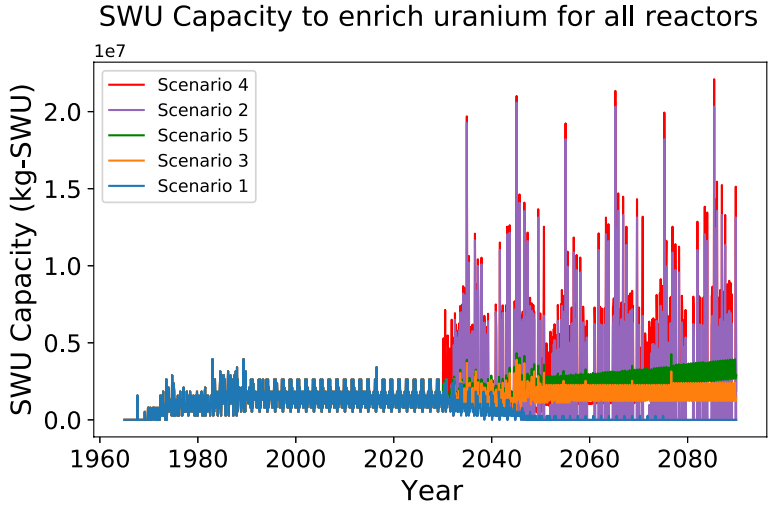

(a) Total SWU required to enrich uranium sent to all reactors at each time step.

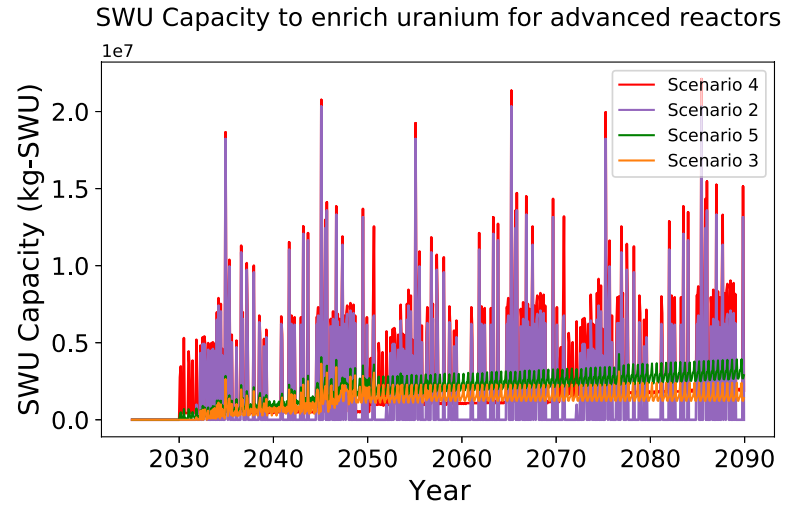

(b) SWU required to enrich uranium sent to advanced reactors at each time step.

Fig. 19. SWU required to enrich natural uranium in all scenarios.

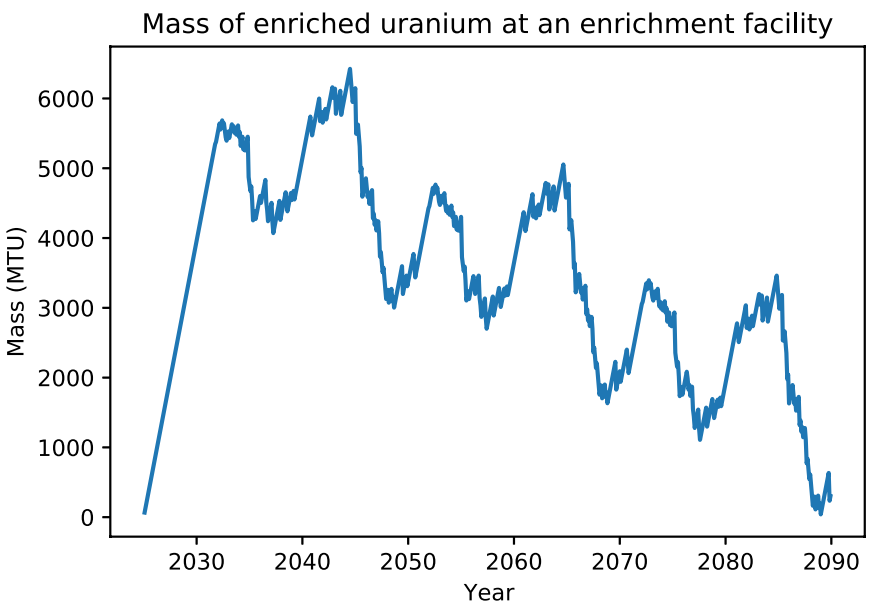

Fig. 20. Net enriched uranium mass stored at a theoretical enrichment facility with a mass throughput of $66 \mathrm{tU} / \mathrm{month}$. This model assumes the facility goes online in 2025 and does not account for any time required for fuel fabrication.

deployed Xe-100 reactors impacts the material requirements and energy produced in those transition scenarios. Another area of future work is to investigate the material requirements if the HALEU demand is met by downblending High-Enriched Uranium (HEU) or enriching uranium of non-natural enrichment, such as LEU below 5\% ${ }^{235} \mathrm{U}$. Finally, an investigation into the optimization of an enrichment facility or the use of other methods to create HALEU to meet the demand of each scenario will provide insight into the logistics of transitioning to HALEU-fueled reactors.

\section{Funding}

This material is based upon work supported under an Integrated University Program Graduate Fellowship.

Acknowledgements The authors thank Dr. Kathryn Huff for her assistance in using the Cyclus software and fuel cycle modeling.

\section{Author contribution statement}

Amanda M. Bachmann: conceptualization, investigation, methodology, formal analysis, writing - original draft and review \& editing, Roberto Fairhurst-Agosta: MMR simulation methodology, writing - review \& editing, Zoë Richter: Xe-100 simulation methodology, writing review \& editing, Nathan Ryan: writing - review \& editing, Madicken Munk: conceptualization, supervision, writing - review \& editing.

\section{References}

1. R. Wigeland, T. Taiwo, H. Ludewig, M. Todosow, W. Halsey, J. Gehin, R. Jubin, J. Buelt, S. Stockinger, K. Jenni, B. Oakley, Nuclear Fuel Cycle Evaluation and Screening - Final Report. Technical Report INL/EXT-1431465, U.S. Department of Energy, 2014

2. J.R. Burns, R. Hernandez, K.A. Terrani, A.T. Nelson, N.R. Brown, Reactor and fuel cycle performance of light water reactor fuel with $235 \mathrm{U}$ enrichments above $5 \%$. Ann. Nucl. Energy 142, 107423 (2020)

3. R. Hernandez, N.R. Brown, Potential fuel cycle performance of floating small modular light water reactors of Russian origin. Ann. Nucl. Energy 144, 107555 (2020)

4. K.D. Huff, M.J. Gidden, R.W. Carlsen, R.R. Flanagan, M.B. McGarry, A.C. Opotowsky, E.A. Schneider, A.M. Scopatz, P.P.H. Wilson, Fundamental concepts in the Cyclus nuclear fuel cycle simulation framework. Adv. in Eng. Softw. 94, 46-59 (2016)

5. Power Reactor Information System (PRIS): Reference and On-line Access Manual. Technical report, INTERNATIONAL ATOMIC ENERGY AGENCY, Vienna (1989)

6. N.E. Todreas, Nuclear Systems. Taylor \& Francis, Boca Raton, FL (2012), 2nd ed.

7. D.G. Cacuci, Handbook of Nuclear Engineering (Springer, New York, 2010)

8. M. Mitchell, USNC Micro Modular Reactor - Project and Fuel, April 2020

9. A.I. Hawari, F. Venneri, Development and Deployment Assessment of a Melt-Down Proof Modular Micro Reactor 
(MDP-MMR). Technical Report 14-6782, 1431209, North Carolina State University, April 2018

10. F. Venneri, J. Chang, C.K. Jo, A. Hawari, Neutronic analysis of a micro modular reactor, in PHYSOR2014: International conference on physics of reactors JAEA-CONF-2014-003, JAEA, Tokai, Ibaraki, Japan (2015)

11. B. Harlan, X-energy Xe-100 Reactor initial NRC meeting, September 2018.

12. M. Hussain, F. Reitsma, M.H. Subki, H. Kiuchi, Advances in Small Modular Reactor Technology Developments. A
Supplement to: IAEA Advanced Reactors Information System (ARIS), Nuclear Power Technology Development Section, Division of Nuclear Power of the IAEA Department of Nuclear Energy, Vienna, Austria, September 2018.

13. A.M. Yacout, J.J. Jacobson, G.E. Matthern, S.J. Piet, D.E. Shropshire, C.T. Laws, VISION-Verifiable Fuel Cycle Simulation of Nuclear Fuel Cycle Dynamics. Waste Management (2006)

Cite this article as: Amanda M. Bachmann, Roberto Fairhurst-Agosta, Zoë Richter, Nathan Ryan, and Madicken Munk, Enrichment dynamics for advanced reactor HALEU support, EPJ Nuclear Sci. Technol. 7, 22 (2021) 